\title{
HONGO ENDOMICORRÍZICO Y BACTERIA FIJADORA DE NITRÓGENO INOCULADAS A Coffea arabica EN VIVERO ${ }^{1}$
}

\author{
Juan Francisco Aguirre-Medina ${ }^{2}$, Daniela Montserrat Moroyoqui-Ovilla ${ }^{2}$, Alexander Mendoza-López ${ }^{2}$, Jorge \\ Cadena-Iñiguez ${ }^{3}$, Carlos Hugo Avendaño-Arrazate ${ }^{2}$, Juan Francisco Aguirre-Cadena ${ }^{3}$
}

\begin{abstract}
RESUMEN
Hongo endomicorrízico y bacteria fijadora de nitrógeno inoculadas a Coffea arabica en vivero. Con el objetivo de determinar el efecto de la inoculación con Azospirillum brasilense y Glomus intraradice en café, se estableció la presente investigación en un vivero en el Campo Experimental Rosario Izapa, Chiapas, México de septiembre de 2005 a abril de 2006. Se utilizó un suelo Andosol-mólico típico de la región cafetalera del Soconusco Chiapas, México. El A. brasilense tuvo una concentración de 100 x $10^{6}$ bacterias por gramo de turba y el hongo micorrízico, cuarenta esporas por gramo de suelo con infección de $95 \%$ en el sistema radical de cebolla. Los tratamientos utilizados fueron los microorganismos solos, la combinación de ambos y el testigo sin inocular que se distribuyeron en un diseño de bloques completos al azar. Se evaluaron variables morfológicas y fisiológicas del rendimiento cada treinta días a partir del segundo mes de siembra durante siete meses y se determinó el contenido de N, P y Ca en el tejido vegetal. Los resultados se analizaron estadísticamente y las diferencias entre tratamientos se compararon de acuerdo a Tukey $5 \%$. Los resultados indican una respuesta diferencial entre los microorganismos. A. brasilense indujo mayor desarrollo radical y la simbiosis doble $G$. intraradices + A. brasilense mejoró el desarrollo del tallo y lámina foliar. El contenido de N, P y Ca se presentó de forma consistente con $G$. intraradices.
\end{abstract}

Palabras clave: Inoculación, particionamiento de materia seca, nitrógeno, fósforo, calcio, café.

\begin{abstract}
Endomycorrhizic fungi and nitrogen-fixing bacteria inoculated in coffee nurseries. In order to study the effect of bio-fertilization of Coffea arabica L. with Azospirillum brasilense and Glomus intraradice a trial was established in a nursery at the experimental station Rosario Izapa, Chiapas, Mexico from September 2005 to April 2006. We used a Andosol-mollic soil typical of the Soconusco coffee region of Chiapas, Mexico. A. brasilense had a concentration of 100 x 106 bacteria per gram of peat and the mycorrhizal fungi of 40 spores per gram of soil with $95 \%$ infection of the root system of onion. The treatments were the microorganisms alone, the combination of both, and the control without microorganism, which were arranged in a randomized complete block design. Morphological and physiological yield components were evaluated every 30 days from the second month to seven months. The content of $\mathrm{N}, \mathrm{P}$ and $\mathrm{Ca}$ in plant tissue was determined. The results were analyzed statistically and differences between treatments were compared according to Tukey $5 \%$. The results indicate a differential response of microorganisms. A. brasilense induced greater root development and the double symbiosis $G$. intraradices + A. brasilense enhanced the development of stems and leaf blades. The content of $\mathrm{N}, \mathrm{P}$ and $\mathrm{Ca}$ are presented in a manner consistent with $G$. intraradices.
\end{abstract}

Key words: Inoculation, allocation of dry matter, nitrogen, phosphorous, calcium, coffee.

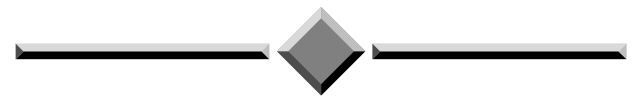

Recibido: 11 de abril, 2010. Aceptado: 16 de mayo, 2011

2 Instituto Nacional de Investigaciones Forestales Agrícolas y Pecuarias. Campo Experimental Rosario Izapa, Chiapas. Km $18 \mathrm{Carretera}$ Tapachula-Cacaohatán, Mpio de Tuxtla Chico, Chiapas, México. aguirre.juan@inifap.gob.mx; moroyoqui.daniela@inifap.gob.mx, mendoza. alexander@inifap.gob.mx, avendano.carlos@inifap.gob.mx, juaguirre86@hotmail.com

3 Colegio de Postgraduados Km. 36.5 Carretera México-Texcoco, Montecillo, Texcoco, Estado de México. CP 56230 México. jocadena@ colpos.mx (aguirre.juan@inifap.gob.mx *autor responsable). 


\section{INTRODUCCIÓN}

En México, las aplicaciones de los hongos endomicorrízicos y las bacterias fijadoras de nitrógeno en las semillas para siembra de maíz, frijol, soya, trigo, sorgo, avena y cebada han favorecido el desarrollo vegetal y reproductivo en los campos de productores (Aguirre-Medina 2006), además en el tejido vegetal y el grano, se ha identificado mayor concentración de nitrógeno y fósforo (Aguirre-Medina 2006, Aguirre-Medina et al. 2007). En el caso de los cultivos perennes, que requieren de etapas previas en viveros o semilleros, se puede explorar estos beneficios durante las etapas iniciales de su desarrollo con el fin de lograr plantas vigorosas (Aguirre-Medina et al. 2007) que soporten el trasplante en condiciones de campo (Sieverding 1991, Vinayak y Bagyaraj 1990).

Tradicionalmente los semilleros o viveros se establecen con suelos de las regiones productoras de café, los cuales son de origen volcánico y se caracterizan por la baja disponibilidad del fósforo (Gutiérrez y Alcalde 1984) y en algunos casos, se aplican desinfectantes al suelo, que seguramente disminuyen las poblaciones de todos los microorganismos ahí presentes y retardan su crecimiento. La producción de plantas en estas condiciones requiere de más de doce meses para su desarrollo y traslado a campo. Se ha demostrado que algunos hongos micorrízicos arbusculares han incrementado el desarrollo vegetal en plantas perennes como Leucaena (Aguirre-Medina y Velasco 1994), Theobroma cacao (Aguirre-Medina et al. 2007) y cítricos (Irizar-Garza et al. 2003), mediante algunos mecanismos como la mayor absorción de nutrimentos a través de las hifas, principalmente fósforo (Marschner y Dell 1994). Otros microorganismos como Azospirillum, también favorecen el crecimiento vegetal en perennes a través de la fijación de nitrógeno y la producción de reguladores del crecimiento (Okon y Kapulnik 1986) como en cacao, (Aguirre-Medina et al. 2007). Cuando se introducen los microorganismos en la semilla y se establece la simbiosis, los beneficios a la planta del cafeto se expresan desde la etapa inicial (Sieverding 1989) y el incremento en el crecimiento se refleja en la disminución del tiempo requerido en vivero (Saggin et al. 1992, Zasoski 1991) para alcanzar el grosor del tallo y el número de cinco a seis ejes o cruces necesarios para ser llevados al campo. Además, se disminuye la mortalidad después del trasplante (Sieverding 1989).
El objetivo de esta investigación fue determinar el efecto de la inoculación con Azospirillum brasilense y Glomus intraradices en café.

\section{MATERIALES Y MÉTODOS}

El experimento se realizó en el campo Experimental Rosario Izapa, Chiapas, localizado geográficamente en el paralelo 140 58 '28" de latitud Norte y 920 09' 19" longitud Oeste del meridiano de Greenwich, a 435 msnm, de septiembre de 2005 a abril del 2006 en condiciones de invernadero. La temperatura media máxima fue de $34^{\circ} \mathrm{C}$, y la mínima de $17^{\circ} \mathrm{C}$ con $85 \%$ de humedad relativa. El suelo utilizado no tuvo tratamiento previo y pertenece al gran grupo de los andosoles mólicos, típico de la región cafetalera del Soconusco, Chiapas, México. El análisis del suelo se realizó en el laboratorio de la Facultad de Ciencias Agrícolas de la Universidad Autónoma de Chiapas, en Huehuetán, Chiapas con las siguientes características: Textura migajón arenosa, 10,3\% de materia orgánica, $\mathrm{pH}$ de 5,7, 0,39\% de $\mathrm{N}$ (Kjeldhal), 10,46 ppm de $\mathrm{P}$ (Olsen), 0,02 cmol $/ \mathrm{kg}$ de $\mathrm{K}, 0,05 \%$ de $\mathrm{Ca}^{2+}, 0,02 \%$ de $\mathrm{Mg}^{++}, 53$ ppm de Fe, 4,7 ppm de $\mathrm{Zn}, 1,3$ ppm de $\mathrm{Cu}$, 16 ppm de Mn, 0,40 ppm de B.

Se sembraron semillas de $C$. arabica var Oro Azteca en macetas con $5 \mathrm{~kg}$ de suelo, las semillas de café se lavaron e impregnaron con el adherente carboximetil celulosa y, sobre éste, se inocularon los microorganismos Azospirillum brasilense y Glomus intraradices. Los inoculantes fueron preparados en laboratorios del Instituto Nacional de Investigaciones Forestales Agrícolas y Pecuarias (INIFAP). A. brasilense en el Campo Experimental Celaya Guanajuato con la cepa proporcionada por el Dr. J. Caballero M. de la Universidad Nacional Autónoma de México (UNAM) en Cuernavaca. La cantidad de bacteria fue de $10^{9}$ por gramo de turba. G. intraradices obtenida en General Terán, Nuevo León y desarrollada en el Campo Experimental Rosario Izapa. La calidad del producto a base de micorriza se logró después de seis meses de establecer la cebolla como planta hospedera. Se evaluó mensualmente la dinámica de la infección y la producción de esporas hasta alcanzar en suelo y raíces el 95\% de infección radical y al menos cuarenta esporas por gramos de suelo. Las plantas se regaron con aproximadamente $100 \mathrm{ml}$ de agua destilada cada tercer día. 
Se utilizaron $6 \mathrm{~g}$ de inóculo de cada microorganismo al momento de la siembra, colocados a una profundidad de tres a cuatro $\mathrm{cm}$ en un orificio donde también se colocaron las semillas.

Se utilizó un diseño experimental de bloques al azar con cuatro tratamientos que consideran efectos simples de los biofertilizantes, las combinaciones de los mismos, además del testigo sin inocular. Se tuvieron seis repeticiones en cada muestreo destructivo realizado cada mes durante seis meses. Se consideró una planta como repetición. Por tratamiento 42 plantas y 168 en todo el experimento.

\section{Variables}

\section{Número de hojas, diámetro del tallo y biomasa}

Se cuantificó el número de hojas totales y diámetro del tallo por planta durante cada muestreo, por tratamiento y repetición. El número de hojas se registró a partir de los 90 días de establecido el estudio. Antes de este tiempo se exhiben solamente las hojas cotiledonales. La biomasa se obtuvo mediante el peso de los componentes fisiológicos de las plantas (raíz, tallo y lámina foliar) en una báscula analítica después de haberse secado en una estufa de aire forzado a 75$80^{\circ} \mathrm{C}$ hasta peso constante (Roberts et al. 1988).

\section{Contenido (\%) de N, P y Ca}

El contenido porcentual de N, P y Ca en el tejido vegetal se analizó en el Laboratorio de Nutrición Vegetal de la especialidad de Edafología del Colegio de Postgraduados en un equipo ICP-AES para los elementos $\mathrm{P}$ y Ca y el contenido de $\mathrm{N}$ por Kjeldhal. Se analizó una sola muestra compuesta de las seis u ocho plantas por tratamiento y muestreo.

\section{Infección micorrízica en raíz}

En los tratamientos con G. intraradices, se cuantificó el porcentaje de colonización con la técnica de Phillips y Hayman (1970), y un microscopio óptico con objetivo de inmersión en 100 segmentos de raíz con longitud aproximada de 1,5-1,6 cm.

\section{Análisis estadístico}

El análisis estadístico se realizó mediante un análisis de varianza, con el procedimiento PROC ANOVA, posteriormente se aplicó una comparación de medias Tukey con un $\alpha \leq 0,05$ con el programa SAS versión 8.0 (SAS 1999-2000) y se graficaron con el programa Sigma plot ver. 7.1 para Windows (Sigma Plot of Jandel Scientific 2001).

\section{RESULTADOS Y DISCUSIÓN}

\section{Componentes morfológicos}

Las plantas que fueron inoculadas con los microorganismos presentaron mayor número de hojas en comparación con el testigo. Entre tratamientos, $G$. intraradices y A. brasilense adheridas por separado a las semillas, indujeron la emisión de más hojas en comparación con el testigo sin inocular y cuando se introdujeron juntos ambos microorganismos.

El mayor incremento en el número de hojas de las plantas inoculadas se considera que se debe a un efecto concomitante entre el aumento en la capacidad de absorción y el transporte del sistema radical, inducido por los microorganismos hacia la planta y la expresión de la planta huésped, a los 120, 180 y 210 dds se presentó en promedio una hoja más en los tratamientos inoculados, aunque no fueron estadísticamente diferentes (Cuadro 1). A. brasilense tiene la capacidad para inducir mayor crecimiento radical en la planta huésped que le permite, además del anclaje, mayor eficiencia en el aprovechamiento de los nutrientes y el agua (Okon et al. 1988) y los hongos micorrízicos, al extender el crecimiento externo del micelio actúa como una extensión de la superficie de absorción de la raíz (Mosse 1973), que se reflejan en su leve incremento en el número de hojas.

El grosor del tallo también se incrementó en las plantas inoculadas con $G$. intraradices y cuando se aplicaron los dos microorganismos, A. brasilense y $G$. intraradices. El efecto se presentó estadísticamente diferente desde los 60, 120, 150 y 210 dds (Cuadro 1). Este mismo hecho ha sido consignado para esta variable por varios autores en diversos cultivos perennes 
Cuadro 1. Comparaciones de medias de número de hojas y diámetro de tallo de plántulas de Coffea arabica L. inoculadas con $A$. brasilense y $G$. intraradices en un suelo andosol-mólico del Soconusco. Chiapas, México. 2006.

\begin{tabular}{|c|c|c|c|}
\hline Días & Tratamiento & $\begin{array}{c}\text { Número } \\
\text { de hojas* }\end{array}$ & $\begin{array}{c}\text { Diámetro del } \\
\text { tallo }(\mathrm{cm})^{*}\end{array}$ \\
\hline \multirow[t]{6}{*}{60} & Testigo & & $0,61 \mathrm{~b}$ \\
\hline & Azospirillum brasilense & & $0,65 \mathrm{~b}$ \\
\hline & Glomus intraradices & & $1,00 \mathrm{a}$ \\
\hline & Azospirillum brasilense + & & $1,03 \mathrm{a}$ \\
\hline & Glomus intraradices & & \\
\hline & & & $\mathrm{CV}=6,4 \%$ \\
\hline \multirow[t]{6}{*}{90} & Testigo & $2,0 \mathrm{a}$ & $1,00 \mathrm{a}$ \\
\hline & Azospirillum brasilense & $2,0 \mathrm{a}$ & $1,00 \mathrm{a}$ \\
\hline & Glomus intraradices & $2,0 \mathrm{a}$ & $1,00 \mathrm{a}$ \\
\hline & Azospirillum brasilense + & $2,0 \mathrm{a}$ & $1,00 \mathrm{a}$ \\
\hline & Glomus intraradices & & \\
\hline & & $\mathrm{CV}=6,6 \%$ & $\mathrm{CV}=3,7 \%$ \\
\hline \multirow[t]{6}{*}{120} & Testigo & $2,5 \mathrm{a}$ & $0,95 \mathrm{~b}$ \\
\hline & Azospirillum brasilense & $3,5 \mathrm{a}$ & $1,00 \mathrm{~b}$ \\
\hline & Glomus intraradices & $3,3 \mathrm{a}$ & $1,15 \mathrm{a}$ \\
\hline & Azospirillum brasilense + & $3,0 \mathrm{a}$ & $1,15 \mathrm{a}$ \\
\hline & Glomus intraradices & & \\
\hline & & $\mathrm{CV}=27,4 \%$ & $\mathrm{CV}=4,4 \%$ \\
\hline \multirow[t]{6}{*}{150} & Testigo & $5,3 \mathrm{a}$ & $1,18 \mathrm{~b}$ \\
\hline & Azospirillum brasilense & $5,6 \mathrm{a}$ & $1,95 \mathrm{a}$ \\
\hline & Glomus intraradices & $5,5 \mathrm{a}$ & $1,91 \mathrm{a}$ \\
\hline & Azospirillum brasilense + & $5,1 \mathrm{a}$ & $1,91 \mathrm{a}$ \\
\hline & Glomus intraradices & & \\
\hline & & $\mathrm{CV}=23,0 \%$ & $\mathrm{CV}=6,0 \%$ \\
\hline \multirow[t]{6}{*}{180} & Testigo & $8,5 \mathrm{a}$ & $1,75 \mathrm{a}$ \\
\hline & Azospirillum brasilense & $9,6 \mathrm{a}$ & $1,93 \mathrm{a}$ \\
\hline & Glomus intraradices & $8,5 \mathrm{a}$ & $1,90 \mathrm{a}$ \\
\hline & Azospirillum brasilense + & $8,6 \mathrm{a}$ & $1,93 \mathrm{a}$ \\
\hline & Glomus intraradices & & \\
\hline & & $\mathrm{CV}=11,3$ & $\mathrm{CV}=7,3 \%$ \\
\hline \multirow[t]{6}{*}{210} & Testigo & $10,8 \mathrm{a}$ & $2,03 \mathrm{~b}$ \\
\hline & Azospirillum brasilense & $10,3 \mathrm{a}$ & $2,41 \mathrm{a}$ \\
\hline & Glomus intraradices & $11,3 \mathrm{a}$ & $2,46 \mathrm{a}$ \\
\hline & Azospirillum brasilense + & $11,1 \mathrm{a}$ & $2,50 \mathrm{a}$ \\
\hline & Glomus intraradices & & \\
\hline & & $\mathrm{CV}=9,2 \%$ & $\mathrm{CV}=8,7 \%$ \\
\hline
\end{tabular}

CV: Coeficiente de variación.

* Valores con la misma letra dentro de cada factor y columna son iguales de acuerdo con la prueba de Tukey con una $\mathrm{P} \leq 0,05$.
(Jaen 1987, Saggin et al. (1992), González-Chavez y Ferrera 1996). En el caso de las plantas de cafeto, la inoculación micorrízica puede aumentar el crecimiento vegetativo, dependiendo de las especies micorrízicas involucradas $\mathrm{y}$, en consecuencia, reducir hasta un $50 \%$ el tiempo necesario para producir en el vivero las plantas de café listas para su trasplante al campo con mayor grosor de tallo.

\section{Componentes fisiológicos}

El mayor peso seco del sistema radical de las plantas de café se obtuvo con la inoculación de $A$. brasilense solo o combinado con $G$. intraradices, pero con diferencia estadística a los 60 y 90 dds, a partir de los 120 días no hubo diferencia. Los altos coeficientes de variación de los muestreos no permitieron la separación entre los tratamientos. Esta respuesta ha sido reportada para diversos cultivos anuales y perennes (Aguirre-Medina 2006). A. brasilense promueve el desarrollo de los pelos radicales (Haahtela et al. 1988, Zimmer et al. 1988) mediante la producción de fitohormonas (Tien et al. 1979, Sarig et al. 1985, MartínezToledo et al. 1988) como el ácido indol acético (AIA) (Tien et al. 1979), y este efecto modifica la morfología y aumenta la biomasa radical (Scout 1972).

El sistema radical extenso generado mediante la inoculación con A. brasilense, favorece el transporte de minerales y agua (Kapulnik et al. 1984, Lin et al. 1983) y a la vez se induce mayor desarrollo de la biomasa. En cambio, cuando se introdujo G. intraradices, se registró menor peso seco del sistema radical en comparación con la introducción de A. brasilense solo o combinado con el hongo micorrízico, pero superior a la biomasa radical del testigo sin biofertilizar (Cuadro 2). Este mismo hecho lo consignan Aguirre-Medina y Velasco (1994) en Leucaena; Aguirre-Medina y Kohashi (2002) en frijol e Irizar et al. (1999) en maíz y frijol. Al parecer la hifa del hongo sustituye los pelos de la raíz y la planta transporta más fotosintatos a la parte aérea para la producción de biomasa.

La colonización micorrízica fue del 12 al $18 \%$ desde el inicio de la evaluación y hasta los 90 dds en los tratamientos con $G$. intraradices y en el testigo de $4 \%$.

El peso seco del tallo principal fue mayor cuando se introdujeron $G$. intraradices y A. brasilense solos o combinados en comparación con el testigo (Cuadro 2). No 
Cuadro 2. Comparaciones de medias de biomasa radical, de tallo y lamina foliar de Coffea arabica L. var. Oro Azteca inoculadas con A. brasilense y G. intraradices en un suelo andosolmólico del Soconusco, Chiapas, México, 2006.

\begin{tabular}{|c|c|c|c|c|}
\hline \multirow[t]{2}{*}{ Días } & \multirow[t]{2}{*}{ Tratamiento } & \multicolumn{3}{|c|}{ Peso seco (g/planta)* } \\
\hline & & Raíz & Tallo & Lámina foliar $^{1}$ \\
\hline \multirow[t]{5}{*}{60} & Testigo & $0,022 \mathrm{ab}$ & $0,0128 \mathrm{a}$ & \\
\hline & Azospirillum brasilense & $0,024 \mathrm{a}$ & $0,0146 \mathrm{a}$ & \\
\hline & Glomus intraradices & $0,017 b$ & 0,0152 a & \\
\hline & $\begin{array}{l}\text { Azospirillum brasilense }+ \text { Glo- } \\
\text { mus intraradices }\end{array}$ & $0,020 \mathrm{ab}$ & $0,0145 \mathrm{a}$ & \\
\hline & & $\mathrm{CV}=19,2 \%$ & $\mathrm{CV}=6,6 \%$ & $\mathrm{CV}=6,6 \%$ \\
\hline \multirow[t]{5}{*}{90} & Testigo & $0,054 \mathrm{ab}$ & $0,020 \mathrm{a}$ & $0,012 \mathrm{a}$ \\
\hline & Azospirillum brasilense & 0,064 a & $0,021 \mathrm{a}$ & $0,014 \mathrm{a}$ \\
\hline & Glomus intraradices & $0,051 \mathrm{ab}$ & $0,021 \mathrm{a}$ & $0,013 \mathrm{a}$ \\
\hline & $\begin{array}{l}\text { Azospirillum brasilense }+ \text { Glo- } \\
\text { mus intraradices }\end{array}$ & $0,048 \mathrm{~b}$ & $0,021 \mathrm{a}$ & $0,015 \mathrm{a}$ \\
\hline & & $\mathrm{CV}=17,5 \%$ & $\mathrm{CV}=6,6 \%$ & $\mathrm{CV}=16,3 \%$ \\
\hline \multirow[t]{5}{*}{120} & Testigo & $0,0571 \mathrm{a}$ & $0,026 \mathrm{a}$ & $0,028 \mathrm{c}$ \\
\hline & A. brasilense & $0,0711 \mathrm{a}$ & $0,028 \mathrm{a}$ & $0,033 \mathrm{bc}$ \\
\hline & G. intraradices & $0,0797 \mathrm{a}$ & $0,030 \mathrm{a}$ & $0,040 \mathrm{ab}$ \\
\hline & A. brasilense $+G$. intraradices & $0,0615 \mathrm{a}$ & $0,031 \mathrm{a}$ & $0,046 \mathrm{a}$ \\
\hline & & $\mathrm{CV}=45,2 \%$ & $\mathrm{CV}=19,2 \%$ & $\mathrm{CV}=18,3 \%$ \\
\hline \multirow[t]{5}{*}{150} & Testigo & 0,059 a & $0,033 \mathrm{a}$ & $0,071 \mathrm{a}$ \\
\hline & A. brasilense & $0,094 \mathrm{a}$ & $0,044 \mathrm{a}$ & $0,091 \mathrm{a}$ \\
\hline & G. intraradices & $0,086 \mathrm{a}$ & $0,041 \mathrm{a}$ & $0,081 \mathrm{a}$ \\
\hline & A. brasilense $+G$. intraradices & $0,092 \mathrm{a}$ & $0,046 \mathrm{a}$ & $0,080 \mathrm{a}$ \\
\hline & & $\mathrm{CV}=28,7 \%$ & $\mathrm{CV}=25,9 \%$ & $\mathrm{CV}=23,1 \%$ \\
\hline \multirow[t]{5}{*}{180} & Testigo & $0,256 \mathrm{a}$ & $0,127 \mathrm{a}$ & $0,26 \mathrm{ab}$ \\
\hline & A. brasilense & $0,281 \mathrm{a}$ & $0,153 \mathrm{a}$ & $0,32 \mathrm{a}$ \\
\hline & G. intraradices & 0,239 a & $0,156 \mathrm{a}$ & $0,29 \mathrm{~b}$ \\
\hline & A. brasilense $+G$. intraradices & $0,262 \mathrm{a}$ & $0,162 \mathrm{a}$ & $0,28 \mathrm{~b}$ \\
\hline & & $\mathrm{CV}=28,7 \%$ & $\mathrm{CV}=24,2 \%$ & $\mathrm{CV}=15,5 \%$ \\
\hline \multirow[t]{5}{*}{210} & Testigo & $0,472 \mathrm{a}$ & $0,221 \mathrm{~b}$ & $0,81 \mathrm{a}$ \\
\hline & A. brasilense & $0,522 \mathrm{a}$ & $0,283 \mathrm{a}$ & $0,85 \mathrm{a}$ \\
\hline & G. intraradices & $0,445 \mathrm{a}$ & $0,267 \mathrm{ab}$ & $0,87 \mathrm{a}$ \\
\hline & A. brasilense $+G$. intraradices & $0,542 \mathrm{a}$ & $0,269 \mathrm{ab}$ & $0,91 \mathrm{a}$ \\
\hline & & $\mathrm{CV}=17,0 \%$ & $\mathrm{CV}=12,6 \%$ & $\mathrm{CV}=12,8 \%$ \\
\hline
\end{tabular}

${ }^{1}$ El primer muestreo corresponde a hojas cotiledonales.

*Valores con la misma letra dentro de cada factor y columna son iguales de acuerdo con la prueba de Tukey con una $\mathrm{P} \leq 0,05$.

se presentan diferencias estadísticas entre tratamientos, seguramente por la influencia de los altos coeficientes de variación en el análisis (25,9 y 24,2). La mayor asignación de biomasa al tallo con los microorganismos se presentó desde los 60 dds y se mantuvo en esta tendencia hasta el final de la evaluación a los 210 dds. 
Algunos autores, en otros cultivos, citan resultados semejantes, como Aguirre-Medina y Velazco (1994) en Leucaena, quienes además, mencionan porcentajes altos de infección micorrízica. Este mismo hecho se consigna en Lycopersicom esculentum, con la inoculación de G. fasciculatum junto con Azotobacter vinelandii, en comparación con la inoculación de los tratamientos por separado (Mohandas 1987).

El peso seco de la lámina foliar también fue superior cuando se introdujeron los microorganismos juntos o separados en comparación con el testigo sin inocular desde el primer muestreo a los 90 dds y estadísticamente diferentes a los 120 y 180 dds. Esta respuesta se mantuvo hasta el final de la evaluación (Cuadro 2).

Entre microorganismos no se encontró una respuesta consistente en esta variable. A. brasilense presenta mayor inducción en el crecimiento de la lámina foliar a partir de los 150 y hasta los 180 dds. G. intraradices no fue superior a $A$. brasilense, pero si fue el mejor tratamiento a los 90, 120 y 210 dds, cuando se aplicaron los dos microorganismos juntos.

La inducción en el desarrollo de mayor lámina foliar con los microorganismos ha sido más evidente en cultivos anuales (Aguirre-Medina 2006), aún cuando, en cacao se presenta una respuesta más consistente con Azospirillum (Aguirre-Medina et al. 2007). En el caso de los hongos micorrízicos el establecimiento inicial es lento. El hongo demanda compuestos ricos en carbono y se establece un flujo de fotosintatos de la parte aérea hacia el sistema radical (Bowen 1987 y Bonfante y Perotto 1992) y es probable que los azúcares durante los dos primeros meses de establecimiento de la colonización no fueron suficientes y la misma tardó en establecerse, lo anterior junto al efecto en la promoción del desarrollo vegetal.

Por otro lado, Fernández et al. (1992) evaluaron tres cepas de hongos micorrízicos (Glomus sp., Acaulospora scrobiculata y G. manihotis) sobre el crecimiento y desarrollo de plantas de cafeto y encontraron incremento del área foliar con respecto al testigo. Resultados semejantes obtuvo Aguirre-Medina et al. (2007), al biofertilizar con los dos microorganismos al cultivo de cacao.

Las experiencias de incrementos en rendimiento en condiciones de campo han sido más evidentes en cultivos anuales. La respuesta benéfica debido a la inoculación de Azospirillum fluctúa frecuentemente en el rango del 5 al 30\% (Okon y Labandera 1994, Dobbelaere et al. 2001, Aguirre-Medina 2001). En el caso de los hongos micorrízicos la respuesta en el rendimiento de maíz ha sido de 4-13\% en Guanajuato (Grajeda-Cabrera 2008) y en Chiapas entre 15 y 29\% (Cruz-Chávez 2008).

\section{Contenido de Fósforo, Nitrógeno y Calcio}

Se analizó una muestra compuesta y sin repeticiones para los nutrientes por tratamiento y muestreo.

El contenido de nitrógeno en el tejido vegetal de las plantas de cafeto fue más alto en el tratamiento inoculado solo con Glomus intraradices (Figura 1). La respuesta se presentó a partir de los 90 dds y se mantuvo hasta el final de la evaluación.

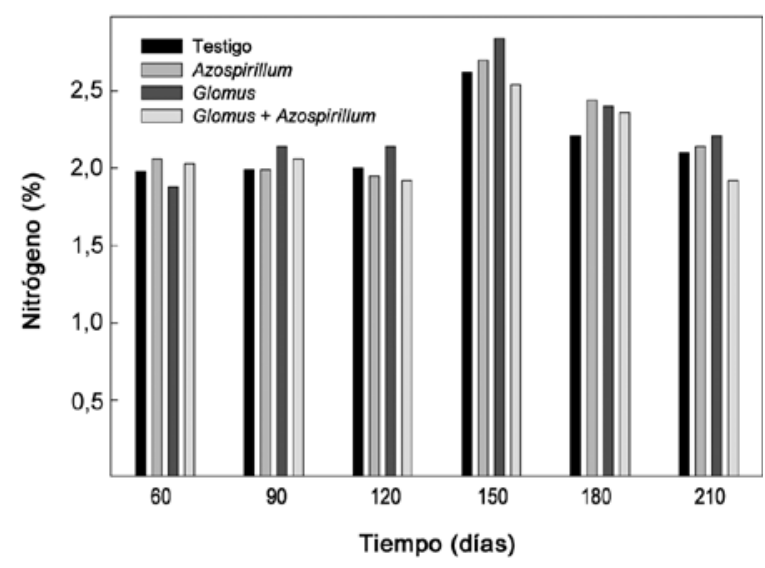

Figura 1. Contenido de nitrógeno en un promedio de ocho plántulas de cafeto (Coffea arabica L.) var. Oro azteca inoculadas con Azospirillum brasilense y/o Glomus intraradices en un suelo andosol-mólico del Soconusco, Chiapas, México. 2006.

En las primeras etapas de desarrollo, el tiempo para identificar el mayor contenido de nitrógeno en la planta parece ser el necesario para que la simbiosis micorrízica se exprese, que es a partir de los 90 dds. Después de los 150 dds, los tratamientos con A. brasilense, también presentan esta misma respuesta. En el caso de Leucaena sembrada en la Costa de Chiapas, también se obtuvieron resultados semejantes (Aguirre-Medina y Velazco 1994). Safir et al. (1972) señalan que los hongos micorrízicos incrementan las concentraciones de N y Ca, y Ames (1987) demostró el transporte del nitrógeno por las hifas de las micorrizas.

El contenido de fósforo en las plantas de cafeto fue superior con los tratamientos que fueron inoculados con los microorganismos solos o en conjunto en comparación con el testigo (Figura 2). 


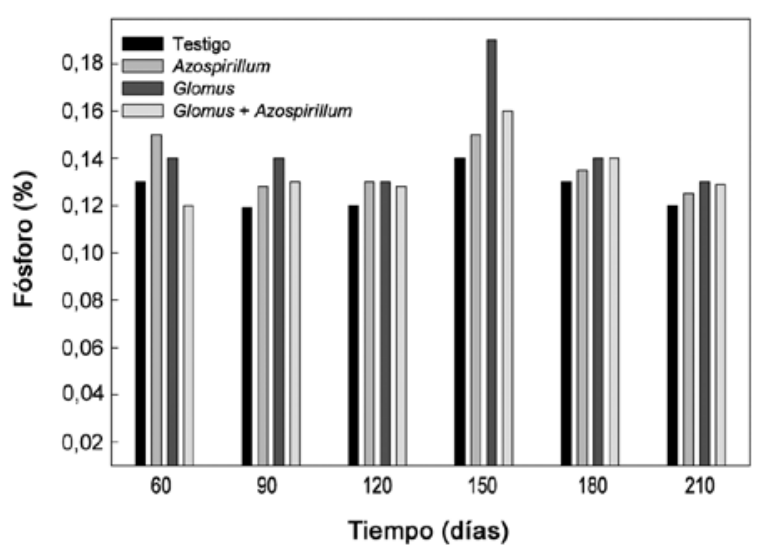

Figura 2. Contenido de fósforo en un promedio de ocho plántulas de cafeto (Coffea arabica L.) var. Oro azteca inoculadas con Azospirillum brasilense y/o Glomus intraradices en un suelo andosol-mólico del Soconusco, Chiapas, México. 2006.

En algunos muestreos, como a los 90, 150 y 210 dds, las mayores cantidades se presentaron en el tratamiento inoculado con G. intraradices. Muchos autores han demostrado que las plantas micorrizadas absorben fósforo del suelo más eficientemente que las plantas no colonizadas (Stribey 1987, Aguirre-Medina y Kohashi 2002) debido a la capacidad de las hifas para explorar mayor volumen de sustrato y con más eficiencia en comparación con un sistema radical no micorrizado (Bolan 1991). Las hifas fúngicas tienen mayor afinidad por el ion fosfato cuando su concentración es baja en la solución (Hayman 1983, Gianinazzi-Pearson y Gianinazzi 1986) y las raíces micorrizadas se mantienen funcionales por más tiempo (Hayman 1983).

En plantas de Coffea arabica L. Siqueira et al. (1993) preinocularon plántulas de café con una mezcla de G. clarum y Gigaspora margarita favoreciendo el crecimiento y la absorción de fósforo por la planta, así como el aumento en la sobreviviencia y la producción en campo.

El contenido de calcio también se incrementó en los tratamientos inoculados, pero con mayor consistencia a partir de los 150 dds (Figura 3).

Estudios con ${ }^{32} \mathrm{P}$ han mostrado que las plantas micorrizadas utilizan con mayor eficiencia los compuestos de baja solubilidad como fosfatos de Fe, Ca y Al predominantes en los suelos ácidos de los trópicos (Fernández et al. 1996). Diversos autores coinciden en señalar que la presencia de los hongos micorrízicos en las plantas

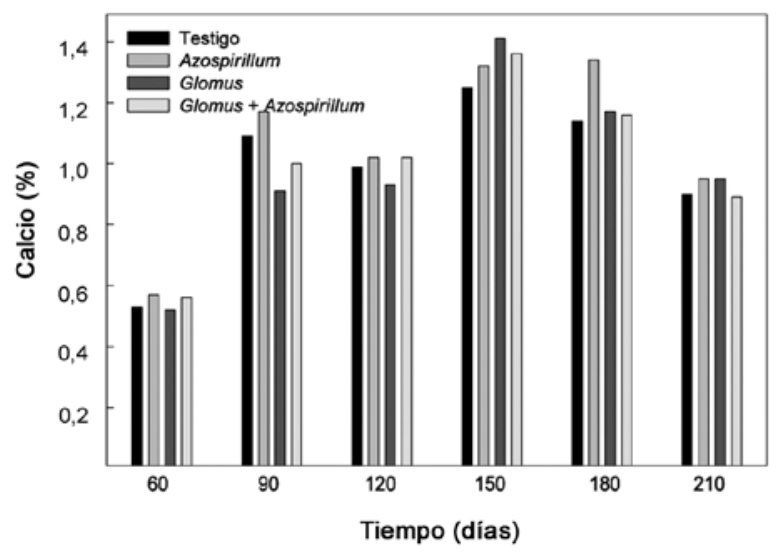

Figura 3. Contenido de calcio en un promedio de ocho plántulas de cafeto (Coffea arabica L.) var. Oro azteca inoculadas con Azospirillum brasilense y Glomus intraradices en un suelo andosol-mólico del Soconusco, Chiapas, México. 2006.

también se asocian, además del fósforo, con el incremento de otros nutrimentos como el $\mathrm{K}, \mathrm{Na}, \mathrm{Ca}, \mathrm{Zn}$, $\mathrm{Cu}$ y Mo. (Bowen et al. 1974, Rhodes y Gerdemann 1978). Estos resultados establecen la importancia de la doble simbiosis en los suelos de baja fertilidad.

El mayor incremento de los tres nutrientes a los 150 días, posiblemente se deba al incremento de los arbúsculos en el sistema radical de la planta. Mosse (1973) cita que la transferencia de nutrientes se sucede de los arbúsculos, hacia las células del sistema radical. En frijol, Aguirre-Medina y Kohashi (2002) identificaron mayor desarrollo de la planta de frijol a los treinta días después de la siembra, y coincidió con un incremento en los arbúsculos en la raíz y posteriormente estas estructuras disminuyen y así mismo el contenido de fósforo. En otros cultivos como trigo, Hetrick et al. (1994), citan que el grado de beneficio de la simbiosis puede no estar relacionado con el grado de colonización de la micorriza.

La inoculación del cafeto en vivero con alguno de los microorganismos solos o combinados, favorece el crecimiento y la materia seca de los componentes morfológicos y fisiológicos del rendimiento en comparación con el testigo sin inocular. Además aumentó en el contenido de N, Py Ca en el tejido vegetal de las plantas de café cuando se inoculan. Las plantas inoculadas con los microorganismos solos presentan mayor contenido de $\mathrm{N}$ y Ca después de los 60 o 90 dds y en el caso del fósforo las concentraciones siempre fueron superiores 
con la inoculación de los microorganismos solos o combinados. Los componentes del rendimiento presentaron un comportamiento diferencial a través del estudio en respuesta a los microorganismos y el tiempo.

\section{LITERATURA CITADA}

Aguirre-Medina, JF; Velasco, ZME. 1994 Componentes morfológicos y fisiológicos del rendimiento de Leucaena leucocephala al inocularse con micorriza VA y/o Rhizobium loti. Agricultura Técnica en México 20(1):43-54.

Aguirre-Medina, JF. 2001. Programa Nacional de Biofertilizantes del INIFAP. Informe de labores. Dirección General de la División Agrícola. México, D. F. 20 p.

Aguirre-Medina, JF, Kohashi-Shibata, J. 2002 Componentes Morfológicos y Fisiológicos del Rendimiento, Dinámica de la Colonización Micorrízica y contenido de Fósforo en Frijol Phaseolus vulgaris L. Agricultura Técnica en México 28(1):23-33.

Aguirre-Medina, JF. 2006. Biofertilizantes microbianos: Experiencias agronómicas del programa nacional del INIFAP en México. Libro Técnico Núm. 2. Instituto Nacional de Investigaciones Forestales, Agrícolas y Pecuarias. Centro de Investigaciones Regionales Pacífico Sur. Campo Experimental Rosario Izapa. Chiapas, México. 201 p.

Aguirre-Medina,JF; Mendoza-López, A; Cadena-Iñiguez, J; Avendaño-Arrazate, C. 2007. La biofertilización del cacao (Theobroma cacao L). en vivero con (Azospirillum brasilense) Tarrand, Krieg et Döbereiner y (Glomus intraradices) Schenk et Smith. Interciencia 32(8):1-6.

Ames, RN. 1987. Localized increase in nodule activity but no competitive interactions of cowpea rhizobia due to pre establishment of vesicular-arbuscular mycorrhiza. New Phytol. 106:207-215.

Bolan, NS. 1991. A critical review on the role of mycorrhizal fungi in the uptake of phosphorus by plants. Plant and Soil 134:189-207.

Bonfante-Fassolo, P; Peroto, S. 1992. Plants and endomycorrhizal fungi: The cellular and molecular basis of their interaction. In Verma, DP. ed. Molecular signals in plant-microbe communications. CRC press Boca Raton, Florida, Usa. p. 445-470.

Bowen, GD; Skinner, MF. Bevege, DJ. 1974. Zinc uptake by mycorrhizal and uninfected roots of Pinus radiata and Araucaria cunninghamii. Soil Biol. and Biochem. 6:141-144.
Bowen, GD. 1987. The biology and physiology of infection and its development. In Safir, G.R. ed. Ecophysiology of VA Mycorrhizal Plants. CRC Press. Boca Raton, Florida, USA. p. 27-57.

Cruz-Chavez, F. 2008. Validación de micorriza arbuscular en parcelas de productores de maíz en Chiapas. Informe anual de Labores del Programa de Biofertilizantes. Campo Experimental Centro de Chiapas. Centro de Investigación Regional del Pacífico Sur. Instituto Nacional de Investigaciones Forestales, Agrícolas y Pecuarias. México. 10 p.

Dobbelaere, S; Croonenborghs, A; Thys, A; Ptacek, D; Vanderleyden, J; Dutto, P; Labandera-Gonzalez, C; Caballero-Mellado, J; Aguirre, JF; Kapulnik, Y; Brener, S; Burdman, S; Kadouri, D; Sang, S; Okón J. 2001. Responses of agronomically important crops to inoculation with Azospirillum. Australian Journal of Plant Physiology 28(9):871-879.

Fernández, F; Cañizares, EG; Rivera, R; Herrera, RA. 1992. Efectividad de tres hongos formadores de micorrizas vesículo-arbusculares (MVA) y una cepa de bacteria solubilizadora de fósforo (BSF)sobre el crecimiento de posturas de café (Coffea arabica L.).Cultivos Tropicales 13(1):23-27.

Fernández, F; Dell-Amico, JM; Fernández, K; Providencia, I de LA; Rodríguez, Y. 1996. Funcionamiento de un inoculante líquido a base de hongo micorrizico arbuscular Glomus sp (INCAM-4) en arroz (Oriza sativa VAR. J-104) en un suelo salino. Cultivos Tropicales 27(2):27-33.

Gianinazzi-Pearson V; Gianinazzi S. 1986 The physiology of improved phosphorus nutrition in mycorrhizal plants. In Physiological and Genetics aspect of Mycorrhizae. Gianinazzi-Pearson, V., Gianinazzi S. eds. INRA Paris. p. 101-109.

González-Chavez MC; Ferrera-Cerrato, R. 1996 Efecto de diferentes dosis de inóculo endomicorrízico en la dinámica de crecimiento de Citrus volkamericana. In Agroecología y desarrollo sostenible. Pérez-Moreno J, Ferrera-Cerrato, R. eds. Área de microbiología. Programa de edafología. Editorial Colegio de Postgraduados. Montecillo. Estado de México. México. p. 374-376.

Grajeda-Cabrera, O. 2008. Desarrollo de manejo de suelo y prácticas de conservación para la producción agrícola sostenible y protección del ambiente. Informe anual de Labores del Programa de Biofertilizantes. Campo Experimental Bajío. Centro de Investigación Regional del Centro. Instituto Nacional de Investigaciones Forestales, Agrícolas y Pecuarias. México. 10 p. 
Gutiérrez, R; Alcalde Blanco, S. 1984. Variaciones de algunas propiedades físicas y químicas en suelos de Ando por la aplicación de abonos orgánicos e inorgánicos. In Santos, T; Miranda, JO. eds. Los suelos de Ando y sus implicaciones en el desarrollo agrícola de la sierra Tarasca. Colegio de Postgraduados. Montecillo, México. p. 39-68.

Haahtela, K; Laakso, T; Nurmiaho-Lassila, EL; Korhonen, TH. 1988. Effects of inoculation of Poa pratensis and Triticum aestivum with root-associated $\mathrm{N}_{2}$ - fixing Klebsiella, Enterobacter and Azospirillum. Plant and Soil 106:239-248.

Hayman, D.S. 1983.The physiology of vesicular-arbuscular endomycorrhizal symbiosis. Canadian Journal of Botany 50:944-963.

Irizar G, M; Albarrán, MM; Aguirre-Medina, JF; Velásquez G; Vargas, P. 1999. Uso de biofertilizantes (Azospirillum, Rhizobium, Micorriza) en maíz, fríjol, trigo y avena. In Informe de labores del Programa de Biofertilizantes en el Campo Experimental Valle de México. Centro de Investigaciones Regionales del Centro. Chapingo México. 10 p.

Irizar-Garza, MBG; Vargas-Vázquez, P; Garza-García, D; Tut Y Couoh, C; Rojas-Martínez, I; Trujillo-Campos, A; García-Silva, R; Aguirre-Montoya, D; Martínezgonzález, JC; Alvarado-Mendoza S; Grajeda-Cabrera, O; Valero-Garza, J; Aguirre-Medina JF. 2003. Respuesta de cultivos agrícolas a los biofertilizantes en la región central de México. Agricultura Técnica en México 29(2):213-225.

Jaen, CD. 1987. Manejo de la endomicorriza vesículo arbuscular en la producción de frutales perennifolios (Carica papaya cv. Cera y Solo) cultivado en vivero. In Pérez-Moreno, J; Ferrera-Cerrato, R. eds. Agroecología y desarrollo sostenible. Área de microbiología. Programa de Edafología. Colegio de Postgraduados. Montecillo. Estado de México. p. 192.

Kapulnik, Y; Gafny, R; Okon, Y. 1984. Effect of Azospirillum spp. inoculation on root development and $\mathrm{NO}_{3}^{-}$ uptake in wheat (Triticum aestivum cv. Miriam) in hydroponic systems. Can. J. Bot. 63: 627-631.

Lin, W; Okon, Y; Hardy, RWF 1983. Enhanced mineral uptake by Zea mays and Sorghum bicolor roots inoculated with Azospirillum brasilense. Appl. Environ. Microbiol. 45:1775-1779.

Marschner, H; Dell, B. 1994. Nutrient uptake in mycorrhizal symbiosis. Plant and Soil 159:89-102.
Martínez-Toledo, MV; De La Rubia, JT; Moreno, J; González-López, JT. 1988. Root exudates of Zea mays and production of auxinas, gibberelines and citokinins by Azotobacter chrococcum. Plant and soil 110:149-152.

Mohandas, S. 1987. Field response of tomatoes (Lycopersicon esculentum Mill "Pusa Ruby") to inoculation with V-A fungus Glomus fasciculatum and with Azotobacter vinelandii. Plant and Soil 98:295-297.

Mosse, B. 1973. The role of mycorrhiza in phosphorus solubilization GIAM IV. Global impacts of Applied Microbiolgy. Fourth International Conference. Sao Paulo, Brasil. J. S. Furtado. ed. p. 543-561.

Okon, Y; Kapulnik, Y. 1986. Development and function of Azospirillum inoculated roots. Plant and Soil 90:3-16.

Okon, Y; Fallik, E; Sarig, S; Yahalom, E; Tal, S. 1988. Plant growth promoting effects of Azospirillum. In Bothe, de Bruijn, Newton. ed. Nitrogen fixation: hundred years after. Gustav Fischer. Stuttgart. p. 741-746.

Okon, Y; Labandera, C. 1994. Agronomic Applications of Azospirillum evaluation of 20 years world wide field inoculation. Soil Biology 26(12):1591-1601.

Phillips, JM; Hayman DJ. 1970. Improved procedures for clearing and staining parasitic and vesicular-arbuscular mycorrhizal fungi for rapid assessment of infection. Trans. Br. Mycol. Soc. 55:158-161.

Roberts, MJ; Long, SP; Tieszen, LL; Beadle, CL. 1988. Medición de la biomasa vegetal y de la producción primaria neta. In Coombs, J; DO Hall, SP Long; JM. Scurloch. eds. Técnicas de Fotosíntesis y Productividad. Colegio de Postgraduados, Chapingo, Estado de México. p. 1-16.

Rhodes, LH; Gerdeman, JW. 1978. Translocation of calcium and phosphate by external hyphae of vesicular-arbuscular mycorrhizae. Soil Sci. 126(2):125-126.

Safir, GR; Boyer, JS; Gerdemann, JW. 1972. Nutrient-status and mycorrhizal enhancement of water transport in soybean. Plant Physiol. 49:700-703.

Saggin, OJ; Siqueira, JO; Colozzi-Filho, A; Oliveira E. 1992. A infesta̧ao do solo com fungos micorrízicos no crescimento post - transplante de mudas de cafeiro nao micorrizadas. Rev. Bras. Cienc. Solo. 16:39-46.

Sarig, S; Kapulnik, Y; Okon, Y. 1985. Effect of Azospirillum inoculation on nitrogen fixation and growth of several winter legumes. Plant and Soil. 90:335-342.

SAS Institute. 1999-2000. SAS/STAT user’s Guide: Versión 8.1 SAS Institute Inc. Cary NC. 
Scout, TK. 1972. Auxin and roots. Annu. Rev. Plant Physiol. 23: $235-258$

Sieverding, E. 1989. Ecology of VAM fungi in tropical agrosystems. Agri. Ecosys. Environ. 29:369-390.

Sieverding, E. 1991. Vesicular-arbuscular mycorrhizae in agrosystems. Technical Cooperation of the Federal Republic of Germany. Echborn, Alemania. In PérezMoreno, J; Ferrera-Cerrato, R. eds. Agroecología y desarrollo sostenible. Área de microbiología. Programa de edafología. Colegio de Postgraduados, Montecillo. Estado de México. p. 241.

Sigma Plot of Jandel Scientific. 2001. User's guide Flying Raichus von. Versión 7.1. SPSS Science Inc. 435 p.

Siqueira, JO; Colozzi-Filho, A; Saggi, OJ; Guimaraes TG; Oliveira, E. 1993. Crescimento de mudas e producao do cafeeiro sob influencia de fungos micorrízicos e superfosfato. Rev. Bras. Cienc. Solo. 17:53-60.
Stribey, DP. 1987. Mineral nutrition. In Safir, GR. ed. Ecophysiology of V-A mycorrhizal plants. CRC Press. Boca Ratón Florida, USA. p. 59.

Tien, TM; Gaskins, MH; Hubell, DH. 1979. Plant growth substances produced by Azospirillum brasilense and their effect on growth of pearl millet (Pennisetum americanun L.). Appl. Environ. Microbiol. 37:1016-1024.

Vinayak K; Bagyaraj, DJ. 1990. Vesicular-arbuscular mycorrhizae screened for Troyer Citrange. Biol. Fertil. Soils 9:311-314.

Zasoski, RJ. 1991. Effects of nitrogen sources and mycorrhizal inoculation with different species on growth and nutrient composition of young coffee seedlings. Café Cacao Thé 35:121-129.

Zimmer, W; Roeben, K; Bothe, H. 1988. An Alternative explanation for plant growth promotion by bacteria of the genus Azospirillum: Planta 176:333-342. 